\title{
PENGEMBANGAN JURUSAN/PROGRAM STUDI DALAM PERSPEKTIF UNIVERSITAS ISLAM NEGERI (UIN)
}

\author{
Muhaimin
}

\section{PENDAHULUAN}

Rencana Strategis Pengembangan STAIN Malang beberapa tahun ke depan yang telah disusun dan disepakati bersama sejak tahun 1997/1998 telah disosialisasikan di berbagai forum, baik dalam forum lokal, nasional maupun regional, termasuk di dalamnya adalah program studi-program studi yang sedang dan hendak dikembangkannya. Bahkan kini mulai ada titik terang untuk menuju proses pengembangan STAIN ke UIN. Fenomena ini akan menuntut perubahan-perubahan cara pandang, sikap, dan kiat para civitas akademika dalam mengembangkan kultur dan tradisi akademik serta memenejberbagai jurusan/program studi yang dikembangkan di lingkungan STAIN, terutama dalam konteks masa transisi menuju ke UIN.

Perubahan secara coersive tersebut perlu dilakukan untuk menghindari kekecewaan publik dan komunitas masyarakat yang menjadi customers, serta berbaliknya persepsi dan image mereka terhadap eksistensi kita.

Perubahan secara coersive tersebut perlu dilakukan untuk menghindari kekecewaan publik dan komunitas masyarakat yang menjadi customers, serta berbaliknya persepsi dan image mereka terhadap eksistensi kita. Dari mana dan bagaimana cara memulainya? Ini merupakan persoalan krusial yang patut difahami oleh masing-masing warga civitas akademika.
Dari mana dan bagaimana cara meinulainya? Ini merupakan persoalan krusial yang patut difahami oleh masing-masing warga civitas akademika.

Namun demikian, sebelum kita melangkah kepada persoalan-persoalan yang lebih operasional, acla baiknya ,dilakukan refleksi terhadap dimensi-dimensi fundasional dari pengembangan STAIN menuju ke UIN. Hal ini dimaksudkan untuk membangun visi dan cara pandang yang relatif sama dalam menangkap dan memahami makna pengembangan STAIN ke UIN, yang kemudian dapat ditindaklanjuti clengan refleksi ke depan untuk sebagai rahmat bagi sekalian alam (Q.S. al-Anbiya': 107).

Ajaran tersebut mengandung makna bahwa setiap muslim dituntut untuk menjadi actor beragama yang loyal, concern dan commitment dalam menjaga dan memelihara ajaran dan nilai-nilai Islam dalam segala aspek kehidupannya, serta bersedia dlan mampu berdedikasi sesuai dengan minat, bakat, kemampuan dan biclang keahliannyà masing-masing dalam perspektif Islam untuk kepentingan kemanusiaan.

Pengembangan lembaga pendidikan Islam, dengan démikian, bertolak dari suatu paradigma bahwa 
pendidikan Islam adalah suatu upaya pengembangan pandangan hidup yang Islami, untuk dimanifestasikan dalam sikap hidup dan ketrampilan hidupnya (manual maupun mental-sosial) selaras dengan minat, bakat, kemampuan dan bidang keahliannya masing-masing. Paradigma ini berimplikasi pada pendidikan Islam yang berorientasi pada peningkatan kualitas iman dan taqwa, atau bahkan iruam bagi orang yang bertaqwa (Q.S. alFurqan: 74). Taqwa ini terwujud dalam dua sikap, yaitu itba'syari'at Allab (mengikuti fundamental doctrine dan fundamental values yang tertuang dan terkandung dalam al-Qur'an dan sunnah Rasulullah) dan sekaligus itba' sunnatillab" (mengikuti aturan-aturan atau hukumhukum Allah yang berlaku di alam semesta).

Sikap orang yang itba' syari'at Allab, ditandai dengan: (1) senantiasa membaca dan memahami ajaran dan nilai-nilai mendasar yang tertuang dan terkandung dalam al-Qur'an dan al-sunnah; (2) berusaha menghayatinya sambil memposisikan diri sebagai pelaku (actor) ajaran Islam yang loyal, di samping sebagai pemikir atau penalar dan pengkaji; (3) memiliki commitment (bukan compliant) yang tinggi terhadap ajaran Islam; dan (4) siap berdedikasi dalam rangka menegakkan ajaran dan nilai-nilai Islam yang rabmatan lial-'alamin. Sedangkan sikap orang yang "itba' sunnatillab" (mengikuti aturanaturan Allah yang berlaku di alam semesta) ditandai dengan: (5) senantiasa membaca dan memahami fenomena alam (karena dirinya merupakan bagian dari dan berada di alam), fenomena fisik dan psikhis (karena dirinya adalah sebagai makhluk individu), fenomena sosial (karena dirinya sebagai makhluk sosial), fenomena historis (karena dirinya berada di atas pentas sejarah), dan fenomena yang lainnya; (6) memposisikan diri sebagai pengamat, pengkaji atau researcher (peneliti), sehingga memiliki daya analisis yang tajam, kritis dan dinamis dalam memahami fenomena yang ada di sekitarnya; (7) senantiasa berusaha membangun kepekaan intelektual serta kepekaan

informasi; dan (8) karena masing-masing orang mempunyaibakat, kemampuan dan minat tertentu, maka dalam itba' sunnatillab perlu disesuaikan dengan kemampuan dar keahlian masing-masing, sehingga terwujudlah kematangan profesionalismenya (Muhaimin, 1999).

Pengembangan kedua itba' (syari'at Allab \& sunnatillab) sekaligus, yang diwujudkan dalam 8 (delapan) indikator sikap tersebut, merupakan landasan normatif-teologis dalam pengembangan STAIN menuju ke UIN, untuk tidak terjebak pada paracligma pengembangan pendidikan Islam yang selama ini berjalan, yang hanya menonjolkan peningkatan dan pengembangan itba'syari'at Allab. Sebagai implikasinya, pengembangan jurusan dan program studi di UIN tidak hanya terbatas pada bidang-bidang yang tercakup dalam

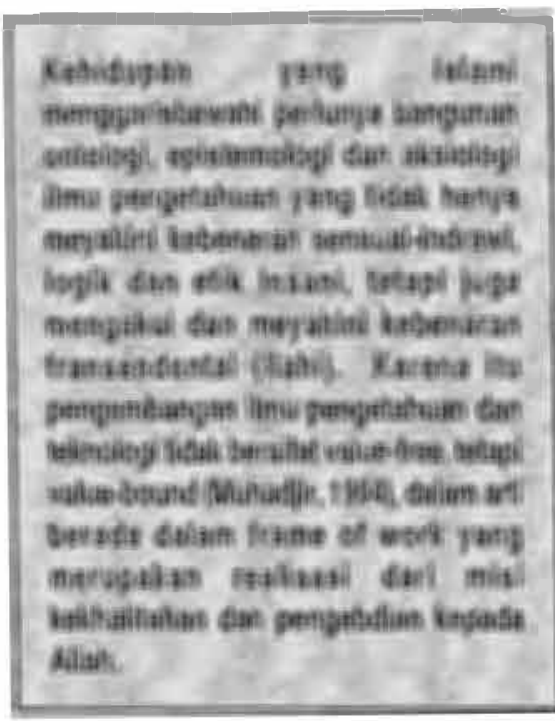
clan produk pencarian, penemuan iptek lewat studi, penelitian dan eksperimen, serta pemanfaatannya dalam kehidupan, merupakan realisasi dari misi kekhalifahan dan pengabdiannya kepada Allah di dunia dalam rangka mencari ridla-Nya dalam kehidupan ukhrawi.

Kehidupan yang Islami menggarisbawahi perlunya bangunan ontologi, epistemologi dan aksiologi ilmu pengetahuan yang tidak hanya meyakini kebenaran sensual-indrawi, logik dan etik insani, tetapi juga mengakui dan meyakini kebenaran transendenial (llabi). Karena itu pengembangan ilmu pengetahuan 
dan teknologi tidak bersifat value-free, tetapi valuebound (Muhadjir, 1994), dalam arti berada dalam frame of work yang merupakan realisasi dari misi kekhalifahan dan pengabdian kepada Allah.

Secara ontologis, ilmu pengetahuan agaknya bersifat netral, dalam arti ia tidak dapat bersifat Islami, kapitalis, sosialis, komunis dan lain-lain. Dalam IPA misalnya, hukum daya tarik (gravitasi) tidak bisa dibawa ke aliran tertentu, demikian pula ilmu-ilmu yang lain. Statement ini benar adanya jika ilmu pengetahuan itu menerangkan "ma buwa ka^in" (hakekat yang ada). Tetapi ketika menjelaskan perubahan yang ada atau apa yang akan terjadi (ma yajibu an yakun), atau menerangkan cara memanfaatkan hukum alam dan mengarahkannya ke arah tertentu, maka ilmu pengetahuan tidak benar bersifat netral. Darwin (1809-1882 M), apakah bisa dikatakan netral ketika mempergunakan peristiwaperistiwa ilmiah untuk mencapai natijah bahwa manusia itu berasal dari kera. Freud (1856-1939), apakah dapat dikatakan netral ketika mempergunakan beberapa fenomena kejiwaan agar mencapai natijah bahwa memberi kebebasan nafsu adalah suatu keharusan. Marx (1817-1883), yang menciptakan

Pengembangan pendidikan Islam, dengan demikian bertolak dari konstruk pemikiran atau epistemologi bahwa yang vertikal (ajaran dan nilai-nllaillahi) merupakan sumber konsullasi, sentral, dan didudukkan sebagal ayat, furcan, rahimah, dan hudan. Sedangkan yang horizontal (pendapat, konsep, teori, Lemuan-temuan ilmu pengetahuan dari sarjana muslim atau non muslim, dan sebagainya) berada dalam posisi sejajar yang saling terjadi sharing ideas, untuk selanjutnya dikonsultasikan kepada ajaran dan nilai-nilaillahi, terutama yang menyangkut will exist (ma yajibu an yakun) atau dimensiaksiologis. teori ekonomi komunis, apakah bisa dikatakan netral ketika menyatakan bahwa benda adalah asal segala wujud dan faktor ekonomi adalah satu-satunya kunci sejarah dan penggerak peristiwa kehidupan ini.

Atas dasar itu, maka ilmu pengetahuan tidak hanya mengajarkan "yang ada" (existence) yang dalam hal ini dapat disebut netral, tetapi juga mengajarkan "yang akan ada" (will exist), bagaimana mempergunakan hakekat universe (alam semesta) dan hukum-hukumnya atau temuan-temuan ilmu pengetahuan, serta bagaimana mengarahkannya ke arah tertentu (aksiologis): Dalam konteks ini, ada dua pilihan, yaitu pilihan Ilahi (keberiaran) atau pilihan manusiawi (hawa nafsu) (Subakir, 1989).

Pengembangan pendidikan Islam, dengan demikian, bertolak dari konstruk pemikiran atau epistemologi bahwa yang vertikal (ajaran dan nilai-nilai Ilahi) merupakan sumber konsultasi, sentral, dan sedangkan yang horizontal (pendapat, konsep, teori, atau non muslim, dan sebagainya) berada dalam posisi sejajar yang saling terjadi sharing ideas, untuk selanjutnya dikonsultasikan kepada ajaran dan nilai-nilai Ilahi, terutama yang menyangkut will exist (ma yajibu an yakun) atau dimensi aksiologis. Pandangan semacam ini akan berimplikasi pada model kurikulum atau program pendidikan dan proses belajarmengajar yang STAIN untuk menuju ke UIN.

Dilihat dari dimensi bistorik, secara garis besar Sejarah (kebudayaan) Islam -'menurut Nasution (1995) - dapat dibagi ke dalam 3 (tiga) periode, yaitu: periode klasik (650 : $1250 \mathrm{M})$, periode pertengahan (1250 - 1800 M), dan periode modern (1800 M s.d sekarang). Dalam realitas sejarahnya, periode klasik menggambarkan masa kejayaan, keemasan atau kemajuan dunia Islam; periode pertengahan menggambarkan masa kemunduran dunia Islam; dan periode modern menggambarkan masa kebangkitan dunia Islam.

Nasution (1995) juga telah memetakản ciri-ciri gerakan ilmiah atau etos keilmuan dari kalangan ulama pada zaman klasik (terutama abad 8-11 M), yaitu: (1) 'melaksanakan ajaran al-Qur'an. untuk banyak mempergunakan akal; (2) melaksanakan ajaran hadits untuk menuntut ilmu bukan hanya "ilmu agama" tetapi juga ilmu yang sampai ada di negeri Cina (bukan ilmu agama); (3) mengembangkan ilmu agama dengan berijtihad dan mengembangkan ilmu pengetahuan (sains) dengan mempelajari dan menguasai ilmu pengetahuan dan filsafat Yunani yang terdapat di Timur Tengah pada zaman mereka, sehingga timbullah ulama figh, tauhicl (kalam), tafsir, hadits, ulama bidang sains (ilmu 
kedokteran, matematika, optika, kimia, fisika, geografi) dan lain-lain; serta (4) ulama yang berdiri sendiri, malahan menolak tawaran sultan menjadi pegawai negeri.

Memperhatikan fenomena di atas nampaklah bahwa dalam realitas sejarahnya, terutama pada periode klasik, pemikiran Islam begitu berkembang dengan pesatnya, sehingga melahirkan kemajuan dunia Islam, baik di bidang ekonomi, pertanian, sains, maupun ilmuilmu keagamaan. Di bidang ekonomi misalnya, Mesir, Suriah, Irak dan Persia ketika itu menjadi pusat perdagangan rempah-rempah, sutera dan lain-lain di Timur Tengah. Hasil-hasil yang berasal dari Timur dibawa ke Barat harus melalui daerah-daerah tersebut. Kairo, Aleksandria, Damsyik, Baghdad dan Siraz (Persia) menjadi kota-kota dagang yang penting. Di bidang pertanian juga mengalami kemajuan. Irigasi lama diperbaiki dan irigasi baru dibangun. Irak menghasilkan gandum, beras, kapas dan kurma, demikian pula Mesir dan Khurasan. Tanah-tanah subur di Bukhara, 'Samarkand, Basrah dan Damsyik menghasilkan buahbuahan dan sayuran. Industri bunga juga dikembangkan, bukan hanya di pekarangan rumah tetapi juga secara besar-besaran untuk keperluan dagang. Di bidang sains, ilmu kedokteran dikembangkan oleh Al-Razi, Ibnu Sina dan Ibnu Rusyd. Ensiklopedi kedokteran yang mereka tulis diterjemahkan ke dalam Bahasa Latin dan dipakai di Eropa sampai abad $18 \mathrm{M}$. llmu kimia mengalami kemajuan di tangan Jabir dan Al-Razi. Matematika dikembangkan oleh Al-Khawarizmi, Umar al-Khayyam dan lain-lain. Observatorium didirikan di Baghdad, Damsyik, Kairo dan kota-kota lainnya. Ilmu hewan berkembang antara lain di tangan Al-Jahiz dan Ibn Miskawaih. Di bidang ilmu keagamaan juga mengalami kemajuan, seperti tafsir, ilmu hadits, fiqih, teologi, filsafat Islam, tasawuf.

Pada periode pertengahan, pemikiran rasional, filosofis dan ilmiah nampaknya mengalami stagnasi dan surut, balkkan hilang dari dunia Islam dan pindah ke Eropa melalui mahasiswa-mahasiswa Barat yang datang belajar ke Andalusia (Spanyol Islam) dan melalui penerjemahan buku-buku Islam ke dalam Bahasa Latin. Di Eropa berkembang Averroisme yang membawa pemikiran rasional, filosofis dan ilmiah dari Ibnu Rusyd (filosof Islam abad $12 \mathrm{M}$ ). Averroisme mendorong la- hirnya Renaisans di Eropa, yang kemudian membawa Eropa ke zaman modem dengan kemajuannya yang pesat dalam sains dan teknologi.

Produktivilas ulama dan umat Islam zaman pertengahan dibandingkan dengan zaman klasik jauh menurun. Produktivitas dalam bidang sains dan filsafat lenyap, sedangkan di bidang ekonomi, industri dan pertanian menurun. Sementara produktivitas di bidang politik yang menonjol, karena masih terdapat tiga negara Islam adikuasa, yaitu kerajaan Turki Usmani, kerajaan Safawi dan kerajaan Mughal. Dengan demikian umat Islam dalam berbagai bidang mengalami kemunduran, sedangkan orang Eropa menikmati kemajuan yang pesat di bidang sains, politik, ekonomi, militer dan lain-lain.

Pada periode modern (abad 19 M), orang Eropa yang dahulunya mundur dan sekarang telah maju itu datang ke dunia Islam. Dunia Islam terkejut dan tidak menyangka bahwa Eropa yang telah mereka kalalikan pada zaman klasik itu, ternyata pada periode modern menguasai mereka. Kerajaan Turki Usmani, adikuasa pada zaman pertengahan (abad $18 \mathrm{M}$ ), mulai mengalami kekalahan dalam peperangannya di Eropa. Napoleon Bonaparte dalam masa tiga minggu dapat menguasai seluruh Mesir pada 1798 M, Inggris memasuki India dan menghancurkan kerajaan Mughal pada 1857 M. Dalam keadaan demikian inilah, dunia Islam bangkit dan muncul kesadaran bahwa mereka telah munclur dan jauh ditinggalkan Eropa. Karena itu timbullah ulama dan para pemikir Islam dengan ide-ide yang bertujuan memajukan dunia Islam dan mengejar ketinggalan dari Barat, sehingga dunia Islam pun memasuki periode modern.

Dengan menyimak pengalaman historik tersebut, maka pengembangan STAIN menuju ke UIN berusaha menangkap ibrah, nilai-nilai, sikap dan cara berfikir dan berperilaku ulama (ilmuwan) pada periode klasik tersebut di atas, karena hal itu dianggap mampu menghadapi tantangan yang makin banyak dan ruwet, yang ditimbulkan oleh kemajuan iptek yang pesat. Sebagai implikasinya, sistem pendidikan Islam yang dibangun dan dikembangkan lewat UIN diharapkan mampu menghasilkan ulama yang bersikap rasional clan profesional; berpandangan luas; berbudi pekerti luhur; pengetahuannya tidak terbatas pada "ilmu keagamaan" saja, tetapi juga mencakup "ilmu pengetahuan umum"; 
serta mampu berdiri sendiri (mandiri).

\section{PENGEMBANGAN KURIKULUM \& PROGRAM STUDI DI UNIVERSITAS ISI.AM NEGERI DALAM KONTEKS HISTORIK}

Sebagaimana uraian tersebut di atas, bahwa dilihat dari perkembangan ajaran Islam dalam realitas sejarahnya, ilmu pengetahuan dalam Islam pernah mengalami kemajuan-yang pesat di tangan para ulama atau cendekiawan muslim pada periode klasik. Hal ini mengandung makna bahwa umat Islam pernah memiliki peradaban Islami di mana ilmu pengetahuan berkembang sesuai dengan nilai-nilai dan kebutuhan-kebutuhan umat Islam. Pengembangan STAIN ke UIN pada dasarnya hendak mengangkat ibrah dari fenomena historik tersebut.

Nasution (1995), ketika mengkaji masalah pembidangan ilmu agama Islam, ia telah mendeskripsikan 'perkembangan ajaran Islam dalam sejarah serta mengelómpokkan ilmu-ilmu Islam berdasarkan fakta sejarah, sebagaimana tertuang pada tabel di bawah ini (kolom-lajur 1). Jika struktur kurikulum dan beberapa program studi yang sedang dan akan dikembangkan di UIN Malang didudukkan dalam konteks historik sebagaimana temuan Harun Nasution (1995) tersebut, maka dapat dipetakan sebagaimana dalam tabel 1 .

Dari pemetaan tabel 1 dapat difahami bahwa pengembangan kurikulum dan beberapa program studi di STAIN untuk menuju ke UIN pada dasarnya dapat dipertanggungjawabkan secara historik, atau setidaktidaknya mendapatkan legitimasi historik. Namun demikian, upaya pemetaan tersebut tidak berpretensi untuk mengadopsi khazanah ulama terdahulu secara taken for granted, tetapi hanya sekadar mempertanggungjawabkan apa yang sedang dan akan dikembangkan di STAIN menuju ke UIN dalam konteks historik Islam. Pengembangan selanjutnya untuk masa kini dan yang akan datang perlu digalakkan dengan berprinsip pada "al-Mubafadbab 'ala al-Qadim al-Shalib wa al-Akbdzu bi al-jadid al-Asblab".

Prinsip tersebut menggarisbawahi perlunya pengembang jurusan clan program studi untuk menghargai karya-karya ulama terdahulu serta mendudukkannya secara proporsional, untuk selanjutnya dilakukan kontekstualisasi dan verifikasi dalam konteks masa kini dan yang akan datang. Hal ini perlu dilakukan agar tidak terjebak pada romantisisme sejarah masa lalu yang dapat menimbulkan sikap statis. Dengan perkataan lain diperlukan adanya keseimbangan antara alMubafadbab dan al-Akbdzu untuk membangun kesinambungan pemikiran dan hasil kajian.

Hanya saja untuk mewujudkan idealisme tersebut agaknya kita masih menghadapi berbagai tantangan. Dalam realitasnya, etos pengembangan ilmu pengetahuan di kalangan kita masih lemah, dan bahkan mengalami kemacetan atau stagnasi. Mengapa demikian? Ada beberapa kemungkinan jawaban terhadap persoalan ini: pertama, mungkin karena terjadi kultus terhadap pemikiran dan hasil temuan ulama atau cendekiawan terdahulu, sehingga karya-karya sesudahnya lebih bersifat repeatation (pengulangan) atau recollection (pengumpulan ulang), dan/atau syarb saja; kedua, mungkin karena lemahnya etos keilmuan atau semangat dosen dalam mengkaji, meneliti dan mengembangkan ilmu pengetahuan \& teknologi, bahkan ironisnya penelitian/pengkajian hanya sebatas memenuhi angka kredit untuk kenaikan pangkat; ketiga, mungkin karena para dosen lebih cenderung untuk menjadi da'i dalam arti sempit;keempat, mungkin karena banyaknya beban jam mengajar mengingat terbatasnya jumlah dosen, atau mobilitasnya tinggi, sehingga seorang dosen mampu mengajar di berbagai perguruan tinggi; dan kelima mungkin karena rendahnya penghargaan terhadap karya ilmiah atau hasil-hasil penelitian (Muhaimin, 1999).

Kelima kemungkinan tersebut merupakan tantangan yang perlu diantisipasi oleh para pimpinan UIN masa depan, serta para pengelola dan pengembang jurusan/ programstudi yang ada di dalamnya, untuk tidak terjebak pada "urijudubu ka 'adamibi" (adanya bagaikan tidak adanya) di tengah-tengah pergumulan dan kompetisi antar berbagai perguruan tinggi yang ada di sekitarnya.

\section{PENUTUP}

Sebagai akhir dari uraian ini, ada baiknya dikemukakan statement Prof. Dr. Mohammad Abdus Salam, salah seorang ilmuwan muslim dari Pakistan yang pernah meraih hadiah Nobel, yang menyatakan: "Tidak diragukan lagi bahwa dari seluruh peradaban di planet 
TABEL I

PETA PERKEMBANGAN IIMU PENGETAHUAN DAIAM SEJARAH ISLAM \& RELEVANSINYA DENGAN PENGEMBANGAN KURIKULUM \& PROGRAM STUDI DI STAIN MENUJU UIN

\begin{tabular}{|c|c|}
\hline PERKEMBANGAN AJARAN ISL̈AM DALAM SEJARAHNYA & $\begin{array}{l}\text { PENGEMBANGAN KURIKULUM \& } \\
\text { PROGRAM STUDI }\end{array}$ \\
\hline $\begin{array}{l}\text { 1. Kelompok Dasar, meliputi: Tafsir, } \\
\text { Hadits, Akidah/I.Kalam (Teologi), Fiqh, } \\
\text { Falsafah Islam, Tasawuf, Tarekat, } \\
\text { Perkembangan Modern (Pembaharuan) } \\
\text { dalam ilmu-ilmu tersebut. }\end{array}$ & $\begin{array}{l}\text { - Dikembangkan dalam Mata } \\
\text { Kuliah Ciri Khusus (MKCK) } \\
\text { Universitas Islam Negeri } \\
\text { (UIN) }\end{array}$ \\
\hline $\begin{array}{l}\text { 2. Kelompok Cabang, meliputi: } \\
\text { a. Ajaran yang mengatur masyarakat: } \\
\text { Ushul Fiqh,Fiqh Muamalah,Fiqh Siyasah, } \\
\text { Peradila, dan Perkembangan Modern di da- } \\
\text { lamnya. Fiqh Muamalah mencakup: peraturan } \\
\text { kemiliteran,kepolisian,ekonomi dan pranata } \\
\text { sosial lainnya. Fiqh siyasah termasuk admi- } \\
\text { nistrasi negara dll. }\end{array}$ & $\begin{array}{l}\text { - Dikembangkan dalam kuriku- } \\
\text { lum Program Studi: } \\
\text { 1. Ilmu Ekonomi } \\
\text { 2. Ilmu Hukum } \\
\text { 3. Ilmu Pengetahuan Sosial }\end{array}$ \\
\hline $\begin{array}{l}\text { b. Peradaban Islam, yang mengandung: } \\
\text { 1) Sejarah Islam (politik,ekonomi,admi- } \\
\text { nistrasi,kepolisian,kemiliteran dll). } \\
\text { 2) Sejarah Pemikiran Islam: I.Kalam,Fil- } \\
\text { safat, dan Tasawuf. } \\
\text { 3) Sains dalam Islam: I.Kedokteran,Mate- } \\
\text { matika,IPA,Astronomi,Optika dll. } \\
\text { 4) Budaya Islam: Arsitektur, kaligrafi, } \\
\text { seni lukis,seni tari, musik dll. }\end{array}$ & $\begin{array}{l}\text { - Dikembangkan dalam kuriku- } \\
\text { lum Program Studi (MKK) } \\
\text { 4. Matematika } \\
\text { 5. Biologi } \\
\text { 6. Fisika } \\
\text { 7. Kimia } \\
\text { 8. Teknik Arsitektur } \\
\text { 9. Kesehatan Masyarakat }\end{array}$ \\
\hline $\begin{array}{l}\text { c. Bahasa dan Sastera Dunia Islam } \\
\text { (Bahasa Arab, Bahasa Inggris, dll.) }\end{array}$ & $\begin{array}{l}\text { - Dikembangkan dalam Mata } \\
\text { Kuliah Keahlian Alat untuk } \\
\text { semua Program Studi. } \\
\text { - Dikembangkan dalam kuriku- } \\
\text { lum Program Studi (MKK): } \\
\text { 10. Bahasa \& Sastera Arab } \\
\text { 11. Bhs. \& Sastera Inggris } \\
\text { 12. Pembelajaran Bhs. Arab } \\
\text { bagi Non-Arab (S2) }\end{array}$ \\
\hline $\begin{array}{l}\text { d. Pengajaran/Pendidikan Islam kepada anak } \\
\text { didik: I.Pendidikan Islam,Filsafat Pen- } \\
\text { didikan Islam,Sejarah Pendiclikan Islam, } \\
\text { Lembaga-lembaga pendidikan Islam, dan per- } \\
\text { kembangan modern di bidang tersebut. }\end{array}$ & $\begin{array}{l}\text { - Dikembangkan dalam kuriku- } \\
\text { lum Program Studi (MKK): } \\
\text { 13. Pendidikan Islam (Tar- } \\
\text { biyah) } \\
\text { 14. Program D2 PGMI } \\
\text { 15. Program Akta IV } \\
\text { 16. Manajemen Pendidikan } \\
\text { Islam (S2) }\end{array}$ \\
\hline $\begin{array}{l}\text { e. Psikologi, yang meliputi: psikologi pendi- } \\
\text { dikan, psikologi perkembangan, kesehatan } \\
\text { mental, dan lain-lain, serta perkembangan } \\
\text { modern di bidang tersebut. }\end{array}$ & $\begin{array}{l}\text { - Dikembangkan dalam kuriku- } \\
\text { lum Program Studi (MKK): } \\
\text { 17. Psikologi }\end{array}$ \\
\hline $\begin{array}{ll}\text { f. } & \text { Penyiaran Islam (dakwah): Sejarah, Materi, } \\
\text { Metode \& Perkembangan modern Dakwah Islam }\end{array}$ & $\begin{array}{l}\text { Dikembangkan dalam Mata } \\
\text { Kuliah Penunjang (MKP) }\end{array}$ \\
\hline
\end{tabular}


ini, sains menempati posisi yang paling lemah dan benarbenar memprihatinkan di dunia Islam. Tidak terlalu berlebihan jika dikatakan bahwa kelemahan ini berbahaya karena kelangsungan hidup suatu masyarakat pada abad ini secara langsung tergantung pada penguasaannya atas sains dan teknologi". Selanjutnya ia menyatakan bahwa: "... ortodoksi agama dan semangat intoleransi merupakan dua faktor utama yang bertanggungjawab atas lemahnya lembaga ilmu pengetahuan yang pernah jaya dalam Islam" (Hoodbhoy, 1996).

Statement tersebut merupakan warning bagi para dosen yang menjadi tiang penyangga utama pengembangan ilmu pengetahuan di perguruan tinggi. Karena itu, diharapkan masing-masing dosen selalu berupaya mengembangkan profesinya yang memiliki beberapa karakteristik sebagai berikut: (1) memiliki kepribadian yang matang dan berkembang; (2) menguasai ilmu pengetahuan atau bidang keahliannya dan wawasan pengembangannya yang bernuansa Islam, karena bagaimanapun seorang dosen yang akan menginspirasi mahasiswanya kepada ilmu pengetahuan dalam perspektif Islam haruslah menguasai ilmu pengetahuan itu sendiri dan sekaligus mampu memberi nafas keislaman, tidak boleh setengah-setengah; (3) menguasai ketrampilan untuk membangkitkan minat mahasiswa kepada ilmu pengetahuan yang bernuansa Islam; dan (4) siap untuk mengembangkan profesi yang berkesinambungan, agar ilmunya dan/atau keahliannya selalu up to date dan tidak out of date. Karena itu, peningkatan studi lanjut, kegiatan-kegiatan penelitian intensif, diskusi, seminar, pelatihan dan lain-lainnya, yang mendukung peningkatan dan pengembangan keahliannya serta mendukung survive-nya jurusan/ program studi.yang dikembangkan di STAIN menuju ke UIN, harus digalakkan dan ditingkatkan secara terus menerus.

\section{DAFTAR PUSTAKA}

Ahmad, Imam Subakir, (1989), Islamisasi Pengetahuan. "Makalah", Disajikan dalam Seminar Sehari Ilmu-Ilmu Sosial, Tgl. 31 Agustus 1989, di IPD Gontor Ponorogo.
Hoodbhoy, Preves, (1996), Ikhtiar Menegakkan Rasionalitas Antara Sains dan Ortodoksi Islam. (Terj.). Bandung: Mizan.

Muhadjir, Noeng; (1994), Metodologi Penelitian Kualitatif. Yogyakarta: Rake Sarasin.

Muhaimin, (1991), Filsafat Ilmu Dalam Perspektif Islam. "Makalah" Disajikan pada Dialog Ilmiah HMI Fakultas Tarbiyah IAIN SA Malang, Tgl. 10 Oktober 1991.

Muhaimin, (1999), Konsolidasi Internal Di Bidang Akademik (Suatu Upaya Pencerahan STAIN Malang di Masa Depan). "Makalah", Disajikan pada Raker STAIN Malang, Tgl. 8-9 Mei 1999.

Muhaimin, (1999), Tema-Tema Pokok Dakwah Islam di Tengah Transformasi Sosial. Surabaya: Karya Abditama.

Nasution, Harun, (1995), Islam Rasional: Gagasan dan Pemikiran. Bandung: Mizan. 